\title{
Миллиметровые радары АО «ПКК Миландр" для применения на автотранспорте и в системах безопасности
}

\author{
Ю. Мякочин ${ }^{1}$, М. Бирюков ${ }^{2}$
}

УДК 621.396 | ВАК 05.27 .01

\begin{abstract}
Высокочастотная (ВЧ) и сверхвысокочастотная (СВЧ) электроника в России имеет богатую историю. Сегодня СВЧ является одним из активно развивающихся направлений во многих областях электроники как специального, так и гражданского назначения. СВЧ-приборы применяются в автомобилестроении, радиосвязи (в том числе в сетях нового поколения 5С), медицине, автоматизации и контроле качества производства, контроле дорожного движения, охранных системах и беспилотных летательных аппаратах. Компания АО "ПКК Миландр" ведет активные работы как по разработке собственных СВЧ-микросхем, так и по созданию приборов СВЧ-электроники, в которых они могут быть применены и востребованы рынком. В статье рассказывается о ряде приборов группы компаний АО "ПКК Миландр" - автомобильном радаре, блоке управления безопасностью автомобиля, однолучевом радаре и СВч-приемопередатчиках, предназначенных для реализации функций интеллектуальной системы помощи водителю (Advanced Driver-Assistance Systems, ADAS) и построения систем контроля дорожного трафика, охраны периметра, определения скорости и дальности объектов.
\end{abstract}

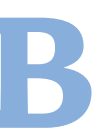

АО «ПКК Миландр» идет разработка автомобильного радара и блока управления безопасностью автомобиля, предназначенных для применения в отечественных системах активной помощи водителю с функциями адаптивного круиз-контроля и автоматического экстренного торможения

Функция адаптивного круиз-контроля регулирует скорость транспортного средства с помощью блока управления безопасностью автомобиля, анализирующего в реальном времени данные, поступающие от радара и камер. Транспортное средство следует за автомобилем, находящимся в том же ряду, сохраняя определенную дистанцию. При этом дистанция, поддерживаемая системой, автоматически корректируется в зависимости от скорости. Если обнаружения транспортного средства впереди не происходит, автомобиль придерживается заданной водителем и сохраненной в памяти скорости. Полное

АО «ПКК Миландр», директор ЦП РЭА, myakochin.y@milandr.ru.

АО «ПКК Миландр", начальник ОРРиП ЦП РЭА,

biryukov.m@milandr.ru. описание системы адаптивного круиз-контроля приведено в ГОСТ Р ИСО 15622-2017.

Функция системы автоматического экстренного торможения заключается в выработке предупредительного сигнала водителю о высоком риске фронтального столкновения с другими объектами (автомобилем, пешеходом, элементом инфраструктуры). В случае если при текущем поведении водителя столкновение неизбежно, должно обеспечиваться автоматическое экстренное торможение. Полное описание системы предупреждения столкновений с движущимся впереди транспортным средством приведено в ГОСТ Р ИСО 15623-2017.

Блок управления безопасностью автомобиля (рис. 1, табл. 1) выполняет функции центрального управляющего устройства в составе системы помощи водителю и осуществляет сбор информации одновременно с двух видеокамер и до трех радаров, обработку информации с целью анализа и принятия водителем или системой решений о возможных действиях. Взаимодействие с автомобилем выполняется по интерфейсу CAN.

Блок управления безопасностью автомобиля содержит многоядерный процессор с блоком видеоускорителя 


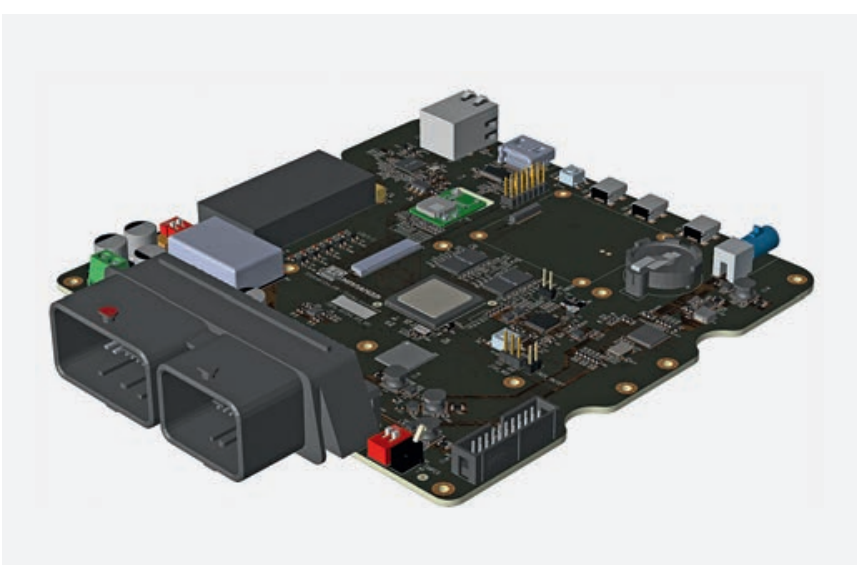

Рис. 1. Внешний вид модуля управления безопасностью автомобиля

для обработки данных, поступающих с радаров и камер; систему синхронного сбора видеоданных с возможностью построения стереоизображения и распознавания окружающей обстановки; систему формирования управляющих команд для автомобиля; интерфейсы приема сигнала с аналоговых и цифровых камер; интерфейсы CAN, Ethernet, USB, Wi-Fi; инерциальную систему для определения перемещений, ускорений и положения автомобиля.

Многоядерный процессор приложений позволяет в режиме реального времени принимать и обрабатывать данные, поступающие с внешних устройств, определять объекты и осуществлять сигнализацию и/или управление автомобилем. Система синхронного захвата изображения с двух камер позволяет формировать стереоизображения для определения глубины получаемого видеоряда. Процессор в исполнении для автомобильных применений содержит 2D и 3D графические ускорители,

Таблица 1. Основные технические характеристики модуля управления безопасностью автомобиля

\begin{tabular}{lc} 
Параметр & Значение \\
Процессор & Cortex A9 \\
\hline Тактовая частота, МГц & 1000 \\
\hline Объем ОзУ, Гбайт & 4 \\
\hline $\begin{array}{l}\text { Объем твердотельного } \\
\text { накопителя, Гбайт }\end{array}$ & 64 \\
\hline Напряжение питания, В & $9-36$ \\
\hline $\begin{array}{l}\text { Интерфейсы } \\
\text { Диапазон рабочих температур, }{ }^{\circ} \mathrm{C}\end{array}$ & PAL, FPD-Link III \\
\hline
\end{tabular}

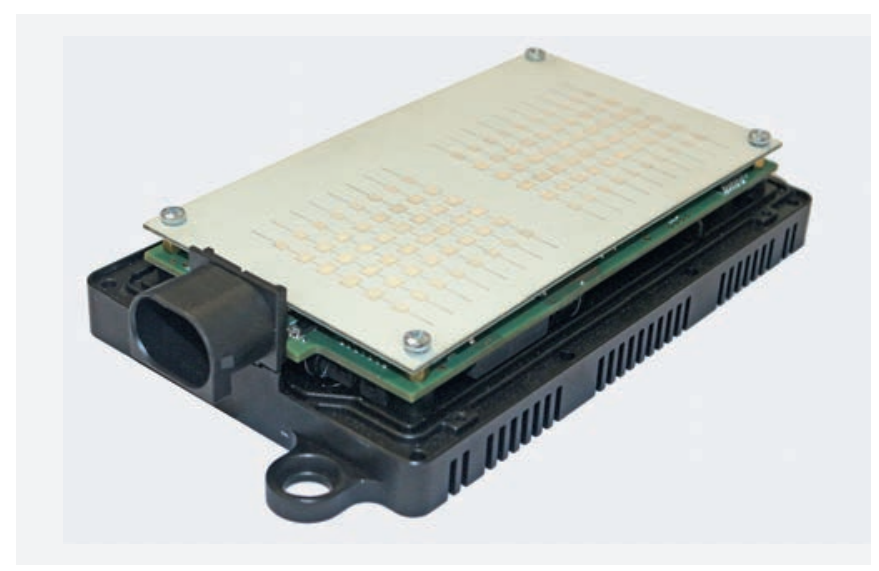

Рис. 2. Внешний вид автомобильного радара "MAPC-2A1"

аппаратный кодек видеоизображения 1080p/30, поддерживает 64-битную память DDR3 / DDR3L. Блок может работать с интерфейсами стандарта FPD-Link III с максимальной пропускной способностью до 3 Гбит / с.

Автомобильный радар (рис. 2, табл. 2) предназначен для идентификации (классификации) и измерения координат (дальности, скорости и азимута) обнаруженных на дороге объектов как в условиях нормальной видимости, так и в условиях, когда визуальное наблюдение затруднено - в ночное время, при плотном тумане, при интенсивном дожде или снегопаде, при сильном задымлении, большой концентрации в воздухе песка и пыли, при ослеплении солнечными лучами, фарами встречных автомобилей. Все обнаруженные объекты классифицируются согласно их габаритам, скорости движения и вероятности достоверного обнаружения. Выходными

Таблица 2. Основные технические характеристики радара "МАРC-2A1"

\begin{tabular}{lc} 
Параметр & Значение \\
Минимальная дальность обнаружения, м & 1,2 \\
\hline Максимальная дальность обнаружения, м & 200 \\
\hline $\begin{array}{lc}\text { Относительные скорости обнаруживае- } \\
\text { мых объектов, км/ч }\end{array}$ & $-400 . .200$ \\
\hline $\begin{array}{l}\text { Число одновременно обнаруживаемых } \\
\text { целей }\end{array}$ & 32 \\
\hline Ширина луча по азимуту, & \\
\hline Напряжение питания, В & $\pm 6 ; \pm 60$ \\
\hline $\begin{array}{l}\text { Интерфейсы } \\
\text { Диапазон рабочих температур, }{ }^{\circ} \mathrm{C}\end{array}$ & $9-36$ \\
\hline
\end{tabular}


данными радара являются кодограммы, содержащие информацию об обнаруженных объектах

Автомобильный радар "МАРС-2АТ» состоит из двух основных компонентов:

- модуля приемо-передатчиков, совмещенного с фазированной антенной решеткой (ФАР);

- модуля цифрового вычислителя.

Передающая ФАР радара излучает непрерывный Вч-сигнал, частота которого изменяется в заданном диапазоне по заранее определенному линейному FMCW (Frequency Modulated Continuous Wave) закону, а амплитуда остается практически неизменной. Излучаемые радаром электромагнитные сигналы, отражаясь от объектов, находящихся в зоне обнаружения, поступают через приемные ФАР на модуль приемо-передатчиков, где, смешиваясь с передаваемым сигналом, образуют разностный сигнал на промежуточной частоте, которая зависит от расстояния и относительной скорости обнаруженного объекта.

Модуль цифрового вычислителя разработан на основе четырех 32-разрядных высокопроизводительных процессоров цифровой обработки сигналов К1967ВН028 (тактовая частота до 450 МГц).

Модуль приемопередатчиков состоит из двух передающих и восьми приемных ФАР, что позволяет формировать цифровым образом желаемую диаграмму направленности (ДН) как на прием, так и на передачу ВЧ-сигнала, благодаря чему автомобильный радар "МАРС-2АТ» имеет возможность работы в режимах дальнего и ближнего действия. Увеличение дальности обнаружения в режиме дальнего действия обеспечивается сужением сектора обзора и уменьшением ширины лучей ДН приемной антенны, что эквивалентно увеличению коэффициента усиления.

Для решения задач построения экономически выгодных систем контроля и подсчета дорожного трафика, определения скорости/дальности объектов и измерения высоты в компании АО «ПКК Миландр" разработана гибкая аппаратно-программная платформа "однолучевой радар".

Однолучевой радар “МАРС-ТАТ» (рис. 3) состоит из модуля приемопередатчика и модуля вычислителя с сигнальным процессором. Приемопередатчик представляет собой компактный модуль, включающий ФАР, реализованную в виде отдельной передающей и отдельной приемной частей. Передающая и приемная части ФАР выполнены симметрично, каждая состоит из отдельных патч-антенн, сориентированных между собой таким образом, чтобы

\footnotetext{
" Мякочин Ю., Бирюков М. Автомобильные радары частотных диапазонов 24 и 77 ГГц // ЭЛЕКТРОНИКА: Наука, Технология, Бизнес 2018. № 8. C. 84-88.
}

была сформирована желаемая ДН и минимизировано взаимное влияние приемника и передатчика.

Модуль цифрового вычислителя разработан на основе 32-разрядного высокопроизводительного процессора цифровой обработки сигналов К1967ВН044 (тактовая частота до 200 МГц).

Гибкость платформы "МАРС-1АТ» заключается в возможности замены модуля приемопередатчика и соответствующего программного обеспечения, что позволяет использовать радар в качестве:

- датчика для систем контроля дорожного трафика (поддерживающего ряд функций: возможность контроля 10 полос движения, измерение средней скорости и количества транспортных средств, определение сквозь барьеры (разделители, островки безопасности));

- высотомера (альтиметра) (измерение высоты с точностью до 10 см, максимальная высота до 60 м; оценка относительной скорости движения; наличие ГЛОНАСС/GPS/Galileo-приемника ПРО-04 АО «НИИМА «Прогресс»);

- измерителя скорости (работа в режиме доплеровского радара, максимальная дальность 200 м, измерение скорости с точностью 1 км / ч, возможность определения направления движения).

Для построения систем контроля и охраны периметра в компании АО «ПКК Миландр» разработана линейка СВЧ-приемопередатчиков. Каждый СВЧ-приемопередатчик представляет собой компактный модуль, включающий ФАР, реализованную в виде отдельной передающей и отдельной приемной частей, схему стабилизации цепей питания, СВЧ-генератор, управляемый напряжением, схему температурной компенсации СВЧ-генератора, квадратурный и синфазный выходы промежуточной частоты,

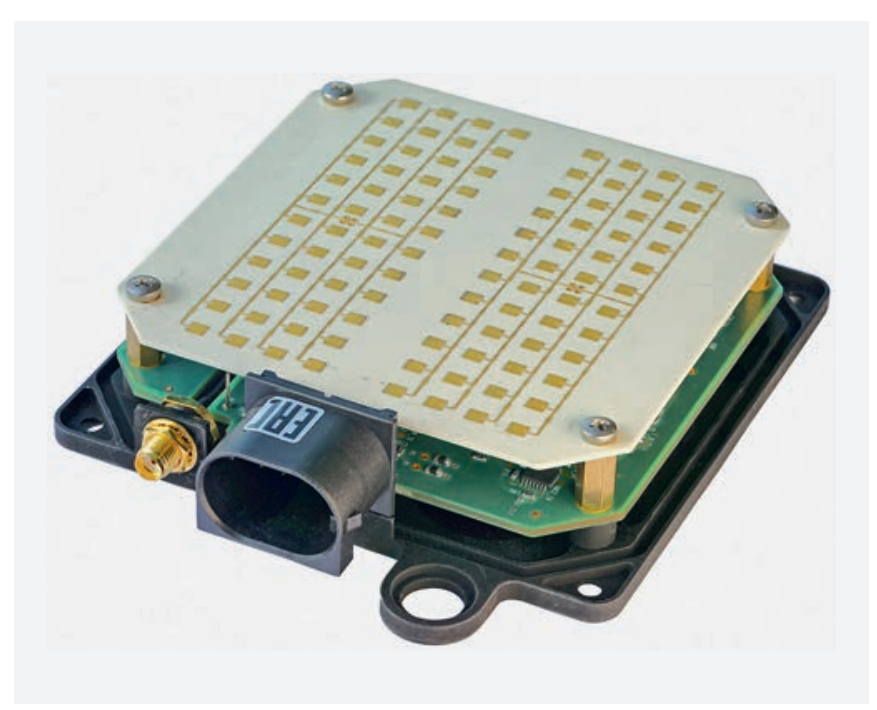

Рис. 3. Внешний вид однолучевого радара "МАРС-1А1" 


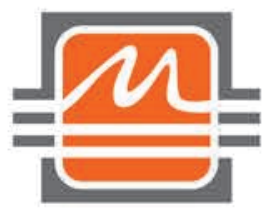

\section{МИКРОСХЕМЫ / ПРИБОРЫ / СИСТЕМЫ}

\section{Разработка и производство}

MURAHIP

ГРУППА КОМПАНИЙ

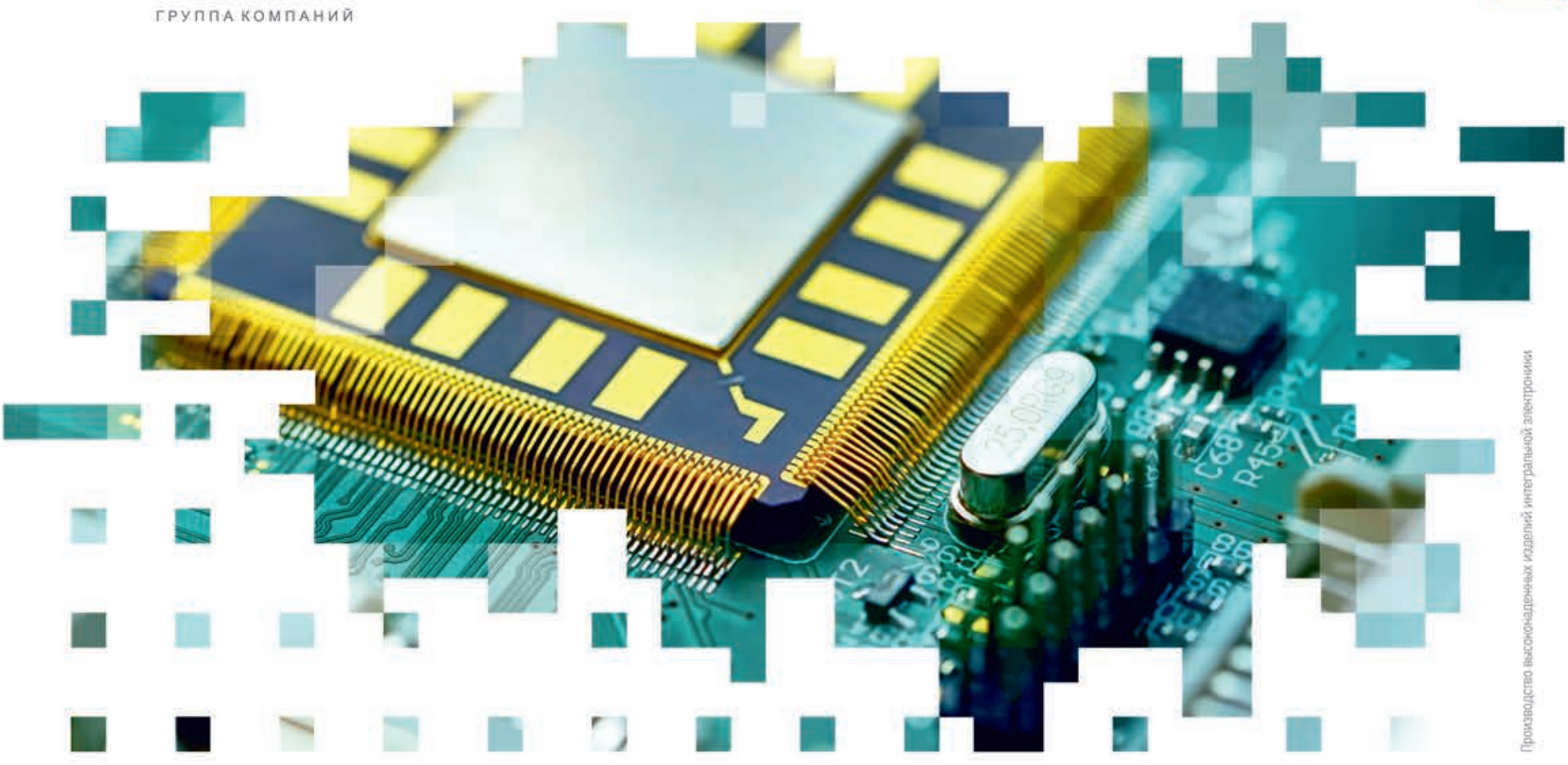

\section{$1923 \mathrm{KX028}$}

Микросхема коммутатора интерфейса Ethernet 10/100/1000 Мбит/с AEHB.431240.329TY

Предназначены для использования в аппаратуре специального назначения, особенно эффективен в приложениях для аудио/видео коммутирующих систем

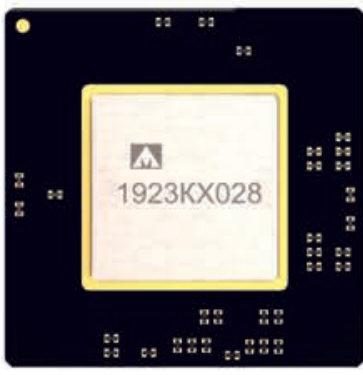

MK 8303.576-2
Технические характеристики

- 16-порт. номмутатор сетей

- IEEE $802.3 /$ Ethernet $10 / 100 / 1000 \mathrm{M6nT/c}$

- $U_{c c}=(3,3 \pm 0,3) B и(1,1 \pm 10 \%) B$

- Поддернка Jumbo пакетов до 9216 байт

- Потребляемая мощность 5 Вт

- QoS совместимая с IEEE $802.1 \mathrm{p}, 1$

- VLAN совместимая с IEEE 802.1Q, 1

- Два MDIO интерфейса со скоростью обмена от 2,5 до 12 Мбит/с

- Общая память пакетов, 1 Мбайт

- Интерфейс SPI master / SPI slave

\section{ТСКЯ.468998.072}

Комплект демонстрационной платы для микросхемы 1923КХ028

Комплект предназначен для ознакомления и исследования работы микросхемы 1923 КХ028

Состав комплекта

- 1923 КХ028 (коммутатор интерфейса Ethernet 10/100/1000)

- 1986ВЕ92 (32-битный микроконтроллер на базе ядра ARM Cortex-M3)

- PCl-Express x1, стандарт 2.0 (5 ГT/c)

- 2 интерфейса SMI (MDIO)

- 8 мезонинных плат с Ethernet PHY трансиверами (2 канала Ethernet на наждой плате)

- USB интерфейс для конфигурирования

- Термодатчик

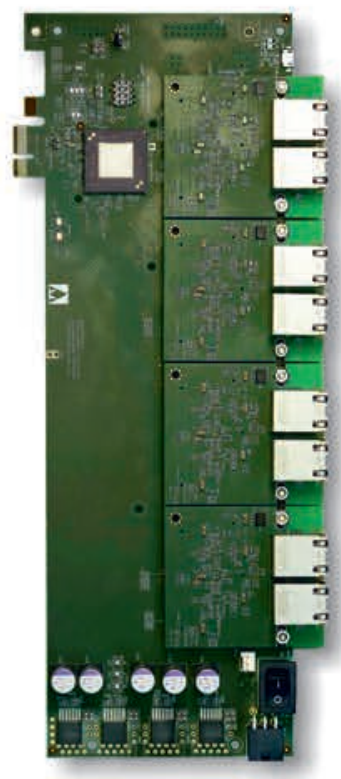

\section{Новизна инженерных решений}

124498, г. Москва, Зеленоград, Георгиевсний пр-т, д. 5 • info@milandr.ru +7 (495) $981-54-33 \cdot+7$ (495) 981-54-36 (факс) 


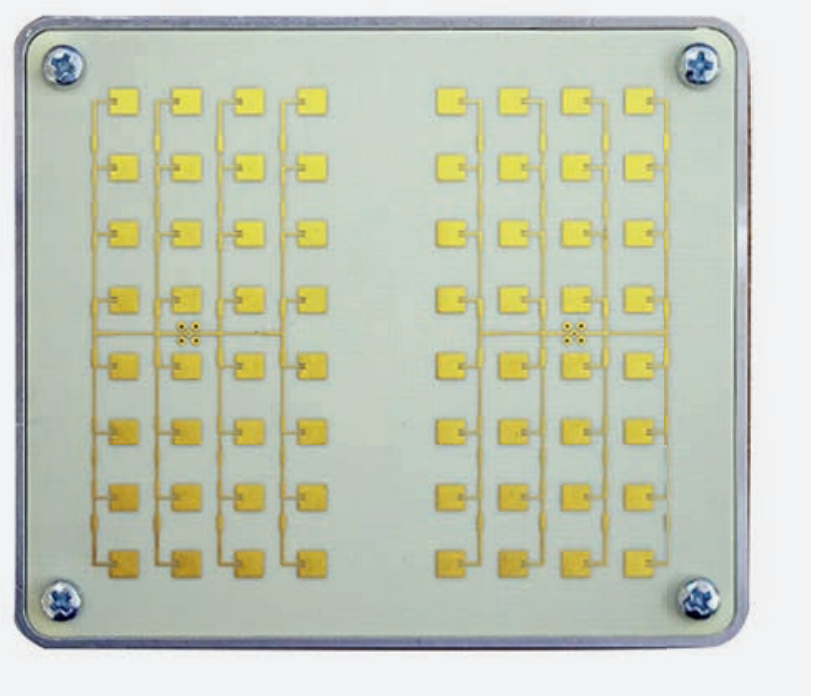

Рис. 4. Внешний вид СВЧ-приемопередатчика «Обзор 24»

два усилителя промежуточной частоты, низкочастотный выход, пропорциональный частоте СВЧ-генератора.

СВЧ-приемопередатчик «Обзор 24» (рис. 4) - высокочувствительный приемопередающий сенсор, оснащенный встроенным малошумящим СВЧ-усилителем (МШУ), позволяющим повысить уровень входного сигнала. СВЧ-приемопередатчик «Обзор 24» имеет габаритные размеры 78×66 мм, коэффициент усиления приемной и передающей антенны 17 дБи у каждой, диаграмму направленности $16^{\circ} / 24^{\circ}$, необходимое напряжение источника питания 5 В, частотный диапазон 24,05-24,25 ГГц. Малые габариты обеспечивают возможность его интеграции в различные виды аппаратуры заказчика.

Св4-приемопередатчик "3авеса 24» (рис. 5) является модификацией устройства "Обзор 24" и отличается увеличенными размерами приемной и передающей ФАР для уменьшения величины угла диаграммы направленности по азимуту. СВЧ-приемопередатчик "Завеса 24" имеет габаритные размеры 202×50 мм, коэффициент усиления приемной и передающей антенны 20 дБи

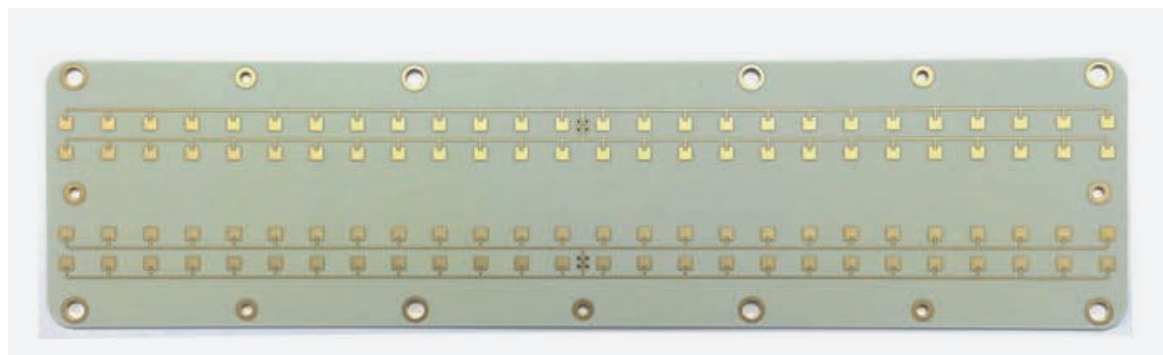

Рис. 5. Внешний вид СвЧ-приемопередатчика "Завеса 24»

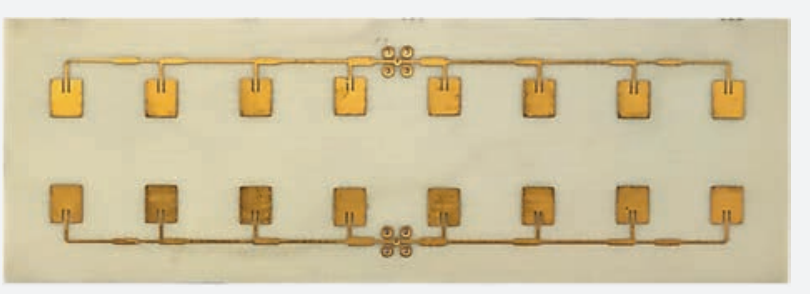

Рис. 6. Внешний вид СВч-приемопередатчика «M-LC6»

у каждой, диаграмму направленности 3\% $/ 56^{\circ}$, необходимое напряжение источника питания 5 В, частотный диапазон 24,05-24,25 ГГц.

СВ4-приемопередатчик "M-LCG» (рис. 6) - также модификация приемопередатчика "Обзор 24». У него уменьшены размеры приемной и передающей ФАР для возможности использования в более компактных применениях. СВ4-приемопередатчик "M-LCG» имеет габаритные размеры 65 ×22 мм, коэффициент усиления приемной и передающей антенны 13 дБи у каждой, диаграмму направленности 12\% $180^{\circ}$, необходимое напряжение источника питания 5 В, частотный диапазон 24,05-24,25 ГГц.

Все разработанные СВЧ-приемопередатчики прошли проверку работоспособности в диапазоне температур от -40 до $85^{\circ} \mathrm{C}$ и имеют температурный дрейф (уход) частоты менее 1 МГц/ $/{ }^{\circ} \mathrm{C}$.

Для решения задач, возникающих при проектировании СВЧ-изделий, в компании сформирована СВЧ измерительная лаборатория, укомплектованная передовым оборудованием. В состав лаборатории входит: безэховая камера (БЭК), программно-аппаратный автоматизированный комплекс построения трехмерной диаграммы направленности, анализатор цепей с частотным диапазоном до 110 ГГц, анализатор сигналов с частотным диапазоном до 90 ГГц, аналоговый генератор сигналов, работающий на частотах до 50 ГГц.

Назначение БЭК - обеспечение защиты от внешнего электромагнитного излучения (радиопомех) при выполнении антенных измерений и предварительных испытаний на электромагнитную совместимость (ЭМС). Первичная аттестация БЭК проводилась в частотном диапазоне 700 МГц - 40 ГГц, с возможностью расширения до 81 ГГц. БЭК позволяет проводить измерения таких характеристик антенн, как коэффициент усиления, диаграмма направленности, степень кроссполяризации, направление вращения и угол наклона эллипса поляризации; предусмотрено отображение результатов 


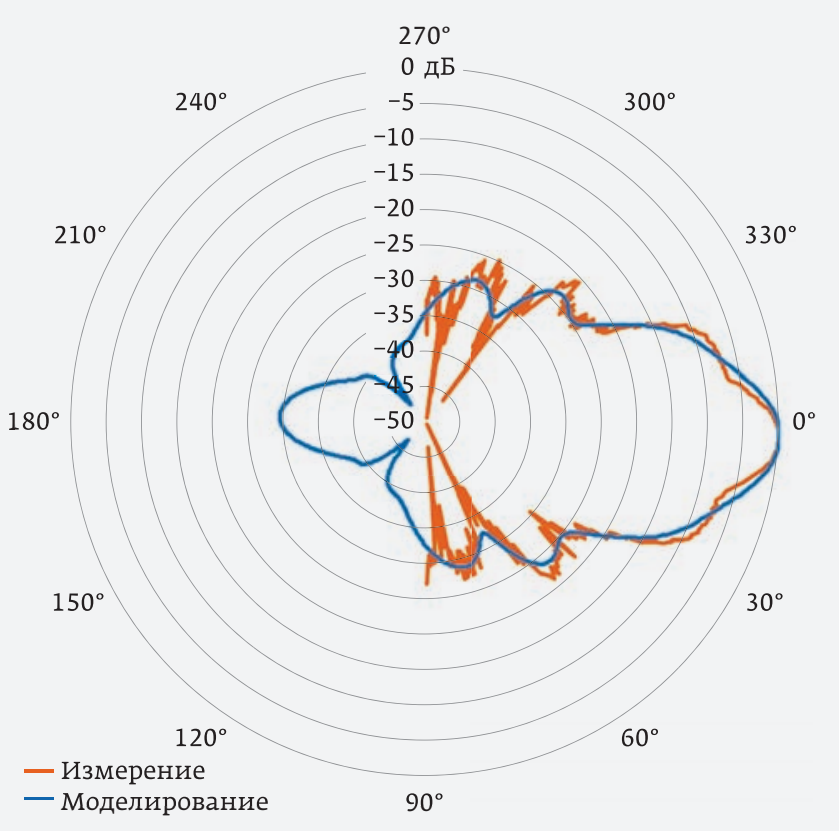

Рис. 7. Сравнение результатов моделирования и измерений диаграмм направленности СВч-приемопередатчика "Обзор 24»

измерения в формате 3D. Измерения проводятся в автоматическом режиме, что значительно повышает их повторяемость.

Разработка СВЧ-изделий невозможна без использования современных систем электромагнитного (ЭМ) моделирования. В компании для нужд ЭМ-моделирования радиоэлектронной аппаратуры закуплены лицензии трех программных продуктов: Cadence Sigrity, Keysight ADS и CST MICROWAVE STUDIO. У каждого из них есть свои сильные стороны. Быстрый и качественный гибридный расчетчик Sigrity PowerSI позволяет без "обрезания"габаритов топологии проводить расчеты многослойных печатных плат размерами 60 × 60 см, при этом можно одновременно рассчитывать до 70 портов. Sigrity PowerDC дает возможность наглядно анализировать качество топологии шин / полигонов земли и питания, а также учитывать возможный перегрев используемых элементов. Keysight ADS позволяет проводить точный расчет более сложных планарных структур и обладает уникальным по функционалу схемотехническим симулятором. CST MICROWAVE STUDIO дает возможность получать модели сложных и объемных 3D-структур, таких как ФАР, проверять и корректировать выбранный тип распределения и ДН разрабатываемых антенн, учитывать влияние корпусов изделий на работу приемопередатчиков и, с другой стороны, оценивать качество экранировки тех изделий, которые должны быть выполнены в соответствии с требованиями электромагнитной совместимости.

Особое внимание уделяется верификации результатов моделирования и обеспечению высокой степени соответствия моделей и проводимых измерений (рис. 7).

В заключение можно отметить, что в настоящее время проходят натурные испытания разработанных СВЧ-приборов в различных условиях их реального применения. АО «ПКК Миландр" сотрудничает с крупными российскими компаниями, работающими в областях автомобилестроения, разработки комплексов охранных систем, контроля дорожного трафика и беспилотных летательных аппаратов.

\section{ГОТОВИТСЯ К ИЗДАНИЮ}

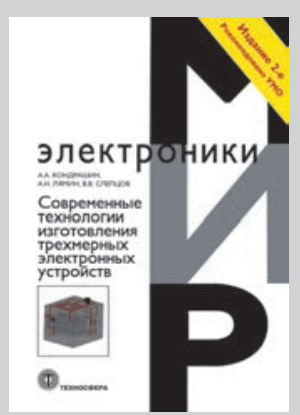

\section{СОВРЕМЕННЫЕ ТЕХНОЛОГИИ ИЗГОТОВЛЕНИЯ ТРЕХМЕРНЫХ ЭЛЕКТРОННЫХ УСТРОЙСТВ: Учеб. пособие. 2-е изд., испр. и доп. \\ Кондрашин А. А., Лямин А. Н., Слепцов В. В.}

С развитием высоких технологий становится реальным выпуск трехмерных электронных устройств (ТЭУ). Решением данной задачи являются еще только разрабатываемые гибридные технологии, названные в данной работе квази-4D-технологиями формирования TЭУ.

Учебное пособие может быть рекомендовано бакалаврам и магистрам высших учебных заведений.

КАК ЗАКАЗАТЬ НАШИ КНИГИ?

凶125319, Москва, а/я 91; †+7 495 234-0110; @+7 495 956-3346; knigi@technosphera.ru, sales@technosphera.ru 